book of eighteen contributors, however ably edited, certain gaps and some inequality of level are inevitable. The articles that extremely pleased the writer of this review were the chapter on the autonomic nervous system and that on the biliary tract, pancreas and spleen-they are models of balanced judgment and lucidity.

The chapters that were disappointing were those on amputations and fractures. In dealing with amputations no notice is taken of the very important recommendations in the Medical Research Council's War Memorandum No. 5, dealing with emergency amputations, and this is a subject of vital interest to the young surgeon in these days. No mention is made of stump bandaging and exercises. The use of a pylon is recommended. Owing to the objections of the leading instrument makers to its use, however, the pylon is no longer used as a routine measure.

The chapter on fractures consists of only 35 pages, and has only one illustration. It shows the correct position in which to put a fractured phalanx.

Economy of space is secured by the omission of such special subjects as anaesthetics, laryngology, and gynaecology. The introduction of a chapter on radiology might therefore appear superfluous, but this valuable chapter does not go into technical details, and is extremely useful in showing the principles of treatment, and the kind of lesion likely to respond, and it will form an excellent basis for co-operation between surgeon and radiologist. If economy of space is needed illustrations of the beam apparatus and the X-ray room, Figs. 6I-62, might be omitted.

Restriction of space has limited description of treatment to one method only as a rule, and one naturally does not always approve the choice, but from the student's point of view it is better to have a clear and definite idea of one good treatment than a hazy, vague idea of several. "The use of a tourniquet on the arm is advocated without showing its dangers and time limit. Other omissions one may have personally regretted, such as the empty vein technique of varicose vein injection, Sorbo rubber on varicose ulcers, and Hey Grove's exposure in a strangulated femoral hernia, but it is impossible to please everyone.

The book is well produced, and for a comparatively small book covering a very wide field, easy and pleasant to read. Not only is the approach to the subject novel, but the arrangement also, and in such chapters as affections of the shoulder region and subsequent chapters much information is brought together that could only be found otherwise with considerable difficulty. It is remarkably free from misprints and slips, and only two were found. In the legend of Fig. 85, "Sternomastoid" should be "Pectoralis Maior." On p. 404 reference to exposure of the phrenic nerve is given as $p .33 r$, it should be $p .381$.

One can highly recommend the book to those for whom it is intended; as well as to many senior practitioners, and even practising surgeons, as providing a delightful "refresher course." It is to be hoped that in subsequent editions the chapters criticised may be revised so that they may correspond to the high level maintained throughout the rest of the book.

\section{CANCER OF THE UTERUS}

By Elizabeth Hurdon, C.B.E., M.D. Oxford University Press, 1942. Price 17 s. 6d.

A record of 1425 consecutive cases of malignant disease of the uterus treated under unified control by radio-therapy cannot fail to be of interest, and it is fitting that the valuable work of the late Miss Hurdon at the Marie Curie Hospital should be recognised by publication. The posthumous appearance of this book is welcome; it has been completed by Miss Martindale and Professor Russ.

A reasoned and fairly comprehensive up-to-date summary of most aspects of the subject is given, but it is, of course, the account of the technique used at the hospital, and the results that make the most interesting reading. The 5 -year survival rates in Stage I and Stage 2 of Carcinoma of the Cervix treated by radio-therapy are $80.0 \%$ and $61.5 \%$. and out of 227 patients surviving to years the corresponding figures are $63.6 \%$ and $41.9 \%$ respectively. These figures speak well for the standard of work attained.

The chapter on cancer of the cervical stump and carcinoma of the cervix complicating pregnancy are of particular interest to the gynaecological surgeon.

Perhaps the title of the book is a little misleading as in addition sections on radiation treatment in non-malignant conditions, malignant disease of the vulva and vagina are included.

\section{SURGICAL CARE: A HANDBOOK OF PRE- AND POST-OPERATIVE TREATMENT}

By R. W. Raven, F.R.C.S., Major R.A.M.C. Edward Arnold. London, 1942. Price ros. 6d.

Mr. R. W. Raven has written a little book on surgical care. Every surgeon who has given this important subject the thought that it deserves has his own particular prejudices and routine. A number of books on this subject have recently appeared, and it is apparent that the matter is receiving more and more attention.

This particular book contains a description of the Miller-Abbott tube, and from the context we wonder whether the author has ever succeeded in passing one. We certainly never have. It always curls up in the stomach. This experience is common to a number of surgeons. Is it because the tubes are British made, and are too stiff, or is it because the tube is passed too late in the disease when there is no peristalsis to carry it into the duodenum? We look forward to seeing more guidance on this point in the next edition.

The book, although a very small one, covers a very wide field. It is not sufficiently detailed to be of value to an operating surgeon, but students, house surgeons, and resident medical officers should find it a great help.

The general practitioner, who occasionally looks after surgical patients, will also find the book a welcome addition to his library. 